\title{
Balancing river restoration measures around a river bifurcation: A case study from the Netherlands
}

\author{
Ralph Schielen ${ }^{1,{ }^{*}, 2}$, Bert Voortman ${ }^{1}$ and Tjeerd Driessen $^{3}$ \\ ${ }^{1}$ Ministry of Infrastructure and Water Management-Rijkswaterstaat, The Netherlands \\ ${ }^{2}$ University of Twente, Faculty of Engineering Technology, The Netherlands \\ ${ }^{3}$ RoyalHaskoningDHV-The Netherlands
}

\begin{abstract}
The Rhine River in the Netherlands still has some characteristics of a delta, although the river is extremely engineered and confined between dikes. An important characteristic are the bifurcation points where the river bifurcates into different branches. The discharge partitioning at the bifurcates is predefined, as this is an important element for the protection of the downstream branches. Adjustable control structures in the vicinity of the bifurcation point facilitate this setting. In order to mitigate higher discharges due to climate change, measures in the floodplains to reduce flood levels are projected. In the planning process, it is important to maintain the discharge partitioning and to guarantee a setting of the control structure such that some control space is left. This can be done by balancing measures. A measure which lowers the flood levels on one branch, should be balanced by another measure on the other branch in order to maintain the correct settings. This requires a careful planning process and careful considerations between flood level lowering and settings of the control structures.
\end{abstract}

\section{Introduction}

The catchment of the Rhine River is one of the most densely populated catchments is the world. With a total area of about $185.000 \mathrm{~km}^{2}$ and a length of $1,233 \mathrm{~km}$ it is one of the biggest and longest rivers in Europe covering Switzerland, Germany and The Netherlands ([1]). Starting at Bonn, Germany, the river is almost completely confined between levees. Downstream of Bonn, between Bingen and Bonn, there is no continuous section of levees. Although the Rhine formally ends in a delta in the Netherlands, the river is not allowed to break free from this confinement. Typical features of a delta, however, remain and these are the bifurcation points where the river bifurcates in multiple branches. In the lower delta there are still many different bifurcation points and hence branches, while in the upper delta, close to the Dutch-German border, there are only two bifurcation points. These divide the main river into three branches (in this paper denoted by their Dutch names, i.e., The Waal River, The Nederrijn River and the IJssel River, see also the situation sketch in figure 2). While in the lower delta, the discharge partitioning is regulated by geomorphological constrains, in

*Corresponding author: ralph.schielen@rws.nl 
the upper delta there are two large control structures that control the discharge partitioning ([3]). The reason for building these constructions can be explained by the system of safety standards in the Netherlands. Levees along the rivers are designed for a particular protection standard which is recorded in Dutch legislation. Downstream of the bifurcation points, the discharge is one of the important components that determines the height and the strength of the levees (piping properties and macro stability are also among the parameters). To ensure the protection of the urban areas near the downstream branches, it is necessary to maintain a predefined discharge partitioning for the river system. If the discharge deviates from this predefined setting, one of the branches gets too much water (the other one gets less), and the downstream levees are not designed for that. That is the reason that large control structures have been constructed in the floodplains adjacent to the bifurcation points to control the discharge partitioning (see figure 1). In figure 2, the location of the two control structures is indicated.
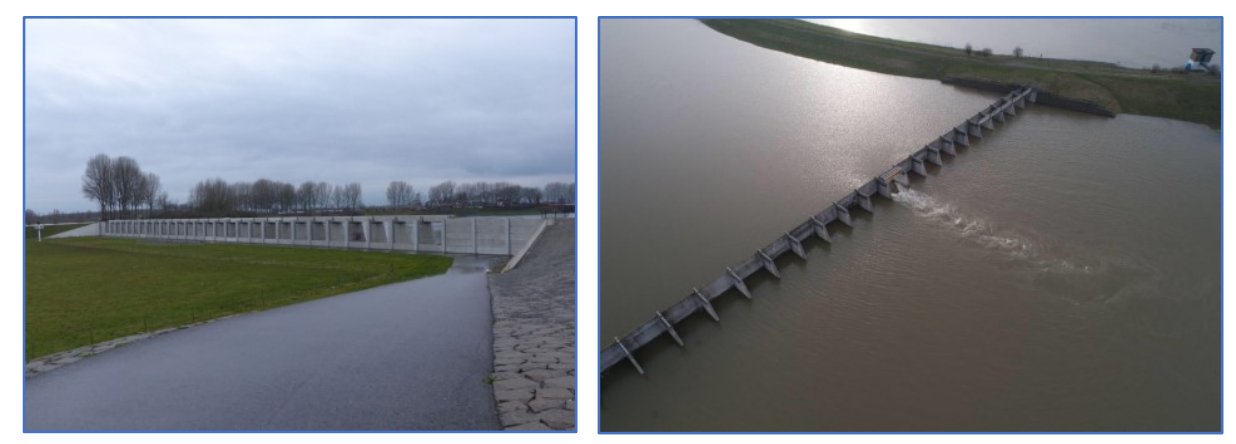

Fig. 1. The southern (left) and northern (right) control structure. Note that the beams which fit in the gates are stored on top of the structure. For the location, see also figure 2. Courtesy Rijkswaterstaat.

In 2015, in the framework of the Dutch Delta Program, a new set of safety standards for the levees of the major rivers, the lakes and the coast has been derived ([4]). These are based on a cost-benefit analysis, and on the condition that the probability per year for an individual to die in a flood-event should be smaller than $1 \times 10^{-5}$. This resulted in a diverse set of safety standards. The Dutch government decided that all levees have to comply with these standards in 2050. Between now and 2050, the old standards remain valid. To comply with the standards, a combination of measures that lower the flood levels at the extreme discharges, and additional dike reinforcements have been suggested. Measures in the neighborhood of the bifurcation points should be planned with care, taking into account that (1) the predefined discharge ration (at extreme conditions) is guaranteed after the construction of the measure, (2) the frequency of inundation of the downstream floodplains at moderate to high discharges (return times 1:25 to 1:100) remains more or less the same and (3) the control range of the control structures remains intact.

This paper describes the process to come to a balanced set of river restoration measures for 2050 that reduces water levels in the river branches, maintains the discharge partitioning at the two bifurcation points and also maintains sufficient control range in the setting of the control structures.

\subsection{Control structures}

There are two (almost identical) control structures located near the two bifurcation points (see also figure 1 and 2). The southern and northern control structures respectively consist out of 32 and 30 gates of 5 meter wide in which a series of beams can be placed. The more 
beams are in the gates, the less discharge can go through the floodplain where the structure is located. The setting of the structure is thus adjustable, suggesting that some level of fine tuning can be achieved. Based on the downstream protection standards, Rijkswaterstaat (the Dutch Water Management Authority) aims at a 64-21-15 percentage partitioning between respectively the Waal, Nederrijn and IJssel River at a design discharge of $16.000 \mathrm{~m}^{3} / \mathrm{s}$ for the Rhine entering the Netherlands. The area where the bifurcation points are located has a dynamic character with changing vegetation and changing geometry due to new measures. Therefore, the setting of the southern structure is determined based on a hydraulic computation with a sophisticated 2D-model of the Rhine branches with the most recent geometry and state of the vegetation that is available. This ensures that whenever the design discharge occurs, the partitioning is conformed to the predefined settings. Uncertainties with respect to e.g. the shape or the height of the discharge wave are not taken into account. These are incorporated in the final design of the dikes. For the northern structure another line of reasoning to determine the setting was chosen. The current setting (after the completion of Room for the River) of that structure is that it is almost completely closed (apart from one open gate). This is due to a decision that for discharges higher than 16.000 $\mathrm{m}^{3} / \mathrm{s}$ at Lobith, the excess discharge is to be equally divided over the IJssel River (the branch going to the north) and the Waal River (the main branch going to the west). This means that the Nederrijn River (the smaller branch that goes to the west) is not supposed to get extra discharge. The reason for this is that an extra discharge would lead to higher levees downstream or to an increase in the discharge capacity in the floodplains along the Nederrijn River. Both are hard to realize: higher dikes are complicated because there is urban development very close to the levee and creating extra discharge in the floodplains is difficult because of the limited space available. This decision has been made in the framework of Room for the River ([5]). However, in 2050 the design discharge is expected to raise to $17.000 \mathrm{~m}^{3} / \mathrm{s}$ due to climate change. To ensure that the Nederrijn River does not get any more discharge, the setting of the northern control structure should change, and by (partially) opening some of the gates. In the sequel of this paper, we will denote this by saying that the average sill level of the structure is lowered. A discharge of $17.000 \mathrm{~m}^{3} / \mathrm{s}$ at Lobith and a partially opened northern control structure is the reference situation for 2050 that we consider in this paper. The 64-21-15 partitioning of the discharge over the bifurcation points (valid to date, at a design discharge of $16.000 \mathrm{~m}^{3} / \mathrm{s}$ ) is then slightly changed to 64-20-16 (at a design discharge of $17.000 \mathrm{~m}^{3} / \mathrm{s}$ ).

The southern structure has a discharge capacity of about $1,500 \mathrm{~m}^{3} / \mathrm{s}$ and is capable of varying the discharge on the Waal River with maximal $530 \mathrm{~m}^{3} / \mathrm{s}$. The northern control structure has a discharge capacity of about $800 \mathrm{~m}^{3} / \mathrm{s}$ and is capable of increasing the discharge of the IJssel River with maximal $220 \mathrm{~m}^{3} / \mathrm{s}$. Ideally, the average sill height in both control structures is half way, which means that there is enough flexibility to increase or decrease the discharge to a certain river branch if needed and to cope with uncertainties and calamities. Although in principle, the northern construction is designed to be adapted during extreme discharge conditions, in reality the setting is assumed to be static during a flood wave.

\subsection{Finding balance}

Because of the increased discharge that is expected in 2050 and to comply with the new safety standards, a combination of additional measures (which reduce the flood levels) combined with dike reinforcement is planned in the framework of the Delta Program ([2]). Recall that in 2050, the northern control structure is partially open.

In the Delta Program, a larger set of measures has been proposed and as far as these have only a limited effect on the flood levels around the bifurcation points, we consider them as part of the reference situation. Among these are large-impact measures like dike relocations 
and construction of large side channels. For this paper however, it is not necessary to go into the details of those measures. In figure 2, we made a sketch of the bifurcation point area, and indicate the flood plains where possibilities for measures are that are described in this paper (in blue), additional measures that we have studied but do not discuss in detail in this paper (in yellow), as well as the location of the control structures (in black).

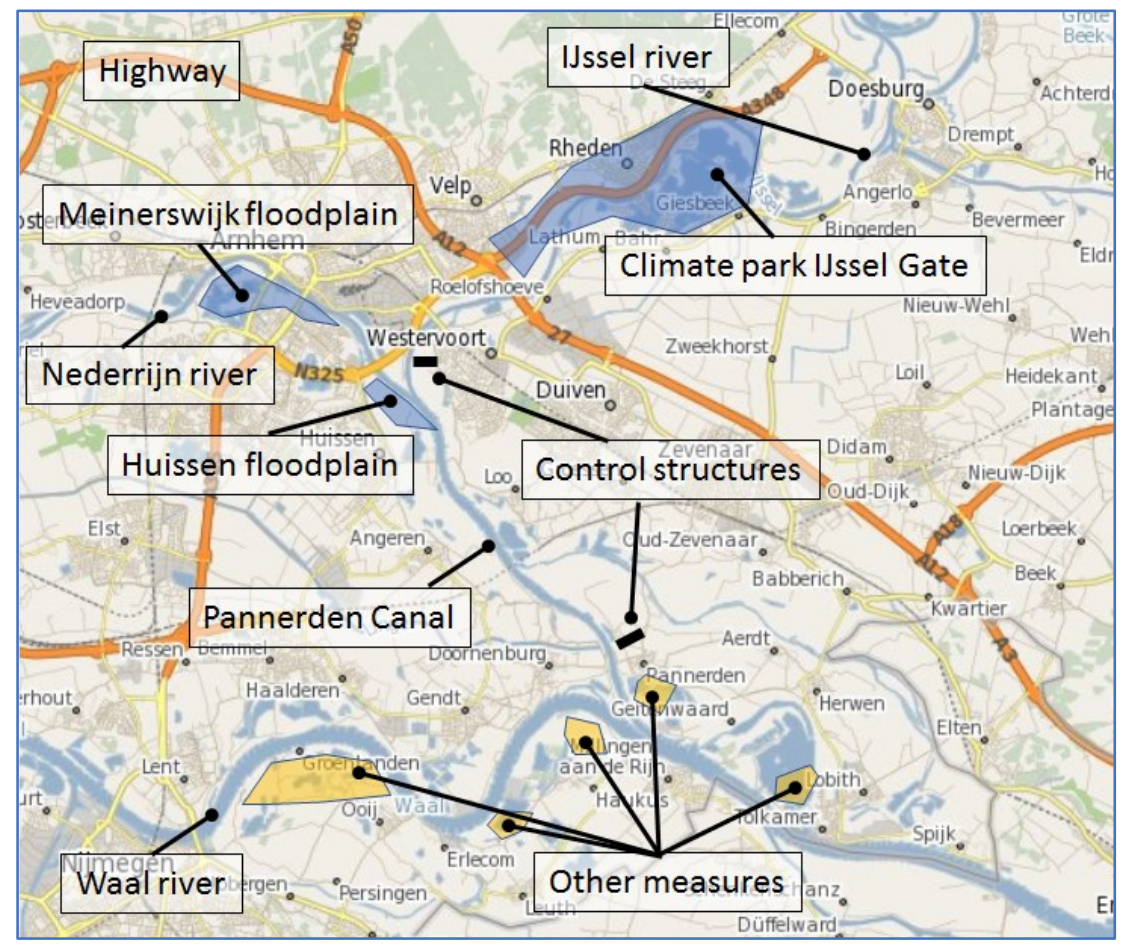

Fig. 2. Location of the measures that balance the discharge partitioning (in blue), measures that are part of the reference situation (in yellow) and the location of the control structures (in black)

One of the main measures that is considered to contribute to reach the safety standards in 2050 is a large measure on the IJssel River, just downstream of the northern bifurcation point and which is called in Dutch Klimaatpark IJsselpoort (in translation: 'Climate Park at the IJssel Gate'), see figure 3. The measure consists out of a drastic restoration of the floodplain, over a stretch of nearly 10 kilometers. It is an initiative of nine national, regional and local authorities, together with nature conservation organizations. There are multiple purposes coupled to this measure: not only enhancing water safety, but also connecting nature areas and improving water quality, enhancing the economic potential of the region and improving the recreational possibilities. With respect to water safety, the elements in the measure that enable flood level reduction is improving the flow patterns and the lowering of some important levees which act as a weir. These measures increase the discharge capacity of the river and hence result in a reduction of the flood water levels. However, due to the close proximity to the bifurcation point, and due to the backwater-effect, it is important to study the consequences for the discharge partitioning between the IJssel River and the Nederrijn River. The measure will obviously increase the discharge to the IJssel, which then becomes too high with respect to the agreed discharge that is allowed to go the IJssel. As a result, the discharge through the control structure should decrease, which is in principle possible by closing more gates. However, the river manager typically wants to avoid the situation where the control structure is completely closed, for that limits the opportunity to 
take into account effects due to uncertainties in geomorphology or discharge. If calculations indicate that this is the case (i.e. a completely closed control structure), one should study the possibilities to restore the balance in the discharge partitioning by constructing measures in the other branches. In this particular case however, calculations show that the effect of Climate Park is so large that the control structure has to be completely closed. Even then, too much discharge is diverted to the IJssel River. A side effect of the closure of the structure is that the backwater curve becomes extremely short, i.e. the measure has a large effect, but the effect lasts only for a few kilometers. The conclusion therefore is that the system is out of balance when constructing the measure Climate Park IJsselgate.

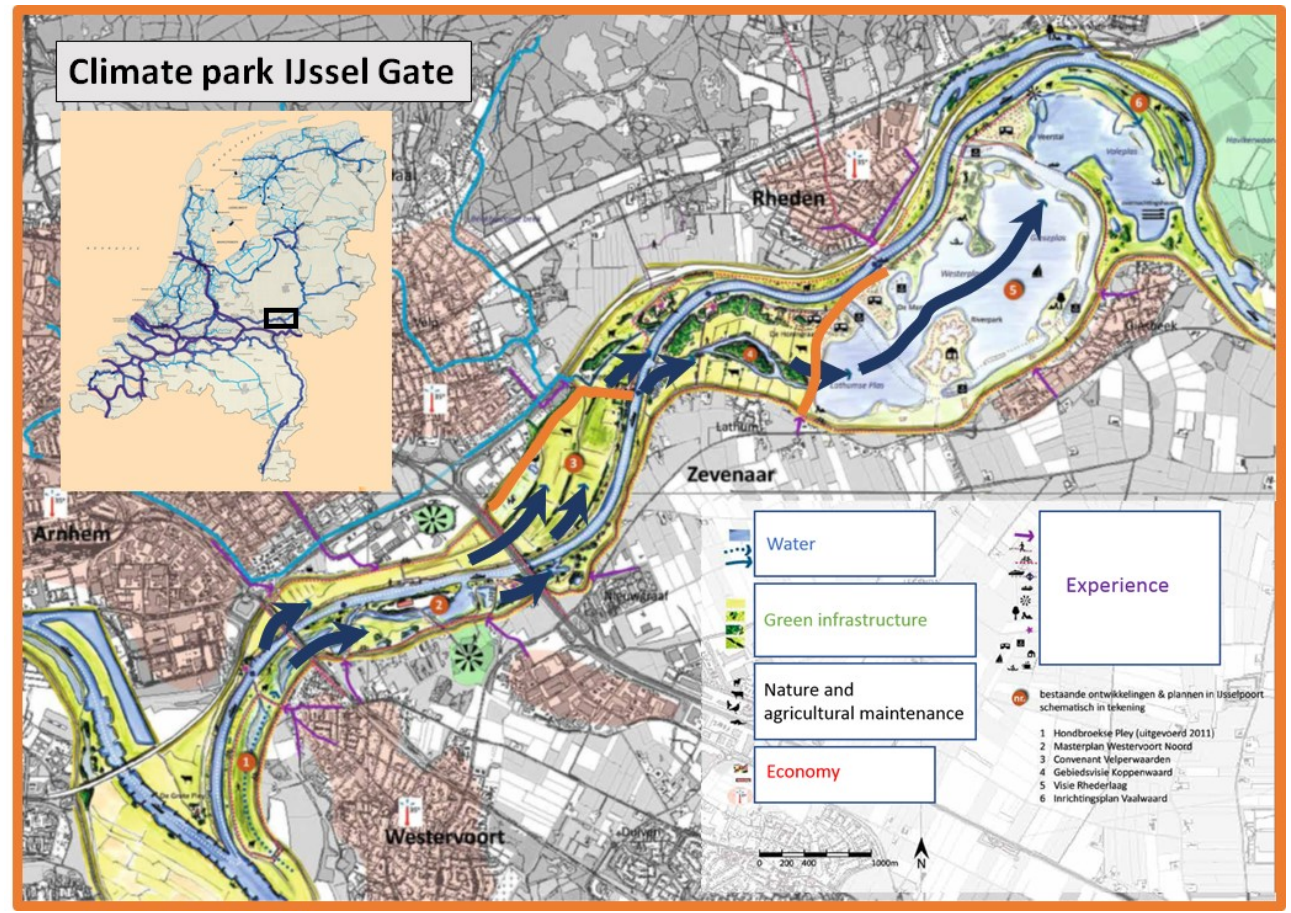

Fig. 3. A detailed sketch of the measure Climate Park at the IJssel Gate. In blue arrows, the intended streamlines at high discharges are indicated and in orange the location of the main weirs is indicated.

\section{Restoring balance}

\subsection{Reducing the effect of Climate Park IJsselgate}

The most obvious way to restore balance is to reduce the effect of the measure of Climate Park IJsselgate, which means that less discharge is diverted to the IJssel River, and consequently, the average sill setting of the control structure can be lowered (and hence, a certain control range is maintained). In this particular case, there are obvious ways to do this, while preserving other benefits such as the contribution to restore nature, restore water quality or improve economic development. This is due to the fact that the main elements that cause the hydraulic effect are two weirs. Lowering them less than originally planned reduces the effect on the flood level. The weirs make this measure very robust from hydraulic point of view as they can be relatively easily adapted for a bigger or smaller effect. Other indicators (attractiveness from landscape or economical point of view) remain unchanged when the height of the weirs is adapted. This means however, that to comply with the new safety 
standards, the levees in the upstream river stretch should be reinforced more than originally planned, unless other measures in the neighborhood can be identified which reduce flood levels but maintain the capacity in the control structures. These measures can be found in the flood plains upstream of Climate Park, along the Pannerdens Canal, and in the flood plains of the Nederrijn. It turns out that just reducing the effect of Climate Park IJsselgate is not sufficient to restore the balance. The northern control structure is still $80 \%$ closed (see figure 5 ) which is considered to be too much. The structure would even be considerably more closed than in the current situation (60\%, see figure 5).

\subsection{Finding balance in the Meinerswijk floodplain and the Huissen floodplain}

Enlarging the discharge capacity in the western flood plain of the Pannerden Canal would result in lowering of the flood levels along the Pannerden Canal and meanwhile, lowering of the sill elevation in the northern control structure. Lowering of this sill elevation is beneficial to restore the flexibility in the northern control structure. The western flood plain is located near the municipality of Huissen which is upstream of the northern control structure. Further upstream these effects on the lowering of the flood levels are dissipated, because the sill elevation in the southern control structure near Pannerden has to be increased to make sure that not too much water is flowing towards the Pannerden Canal. The measure that seems most effective in this flood plain is the construction of a side channel that starts halfway the Pannerden Canal and ends just downstream of the bifurcation point at the beginning of the Nederrijn River (see figure 4). In addition, the groynes at the beginning of the Nederrijn will be lowered with 1.5 meters over a distance of 1.6 kilometers. This measure would be responsible for a lowering of the average sill elevation in the northern control structure of about $50 \mathrm{~cm}$ and of course a lowering of the flood levels along the Pannerden Canal.
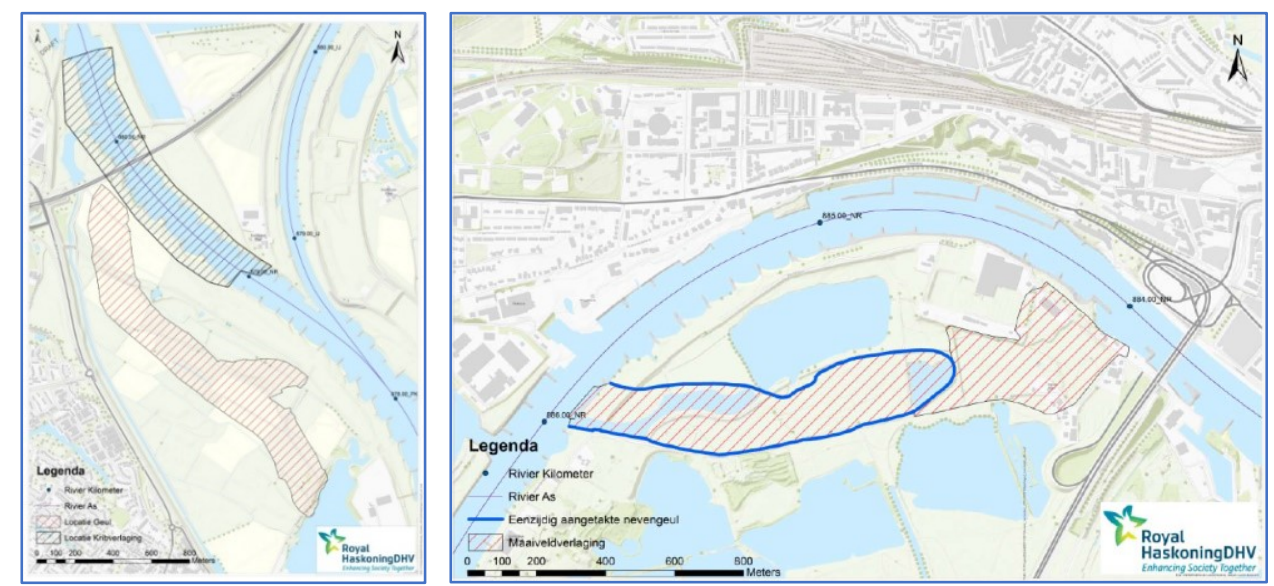

Fig. 4. Overview of the extent of the restoration measure (side channel and groyne lowering, hatched area) in the Pannerden Canal near Huissen (left) and the measure at Meinerswijk (side channel (blue line and hatched area), in combination with flood plain lowering (hatched area)). See also figure 2 for the location of the flood plains.

About 6 kilometers downstream of the bifurcation point on the southbank of the Nederrijn River, there is a large floodplain with ample opportunities for creating additional discharge capacity. In the late 1990-ies, at the upstream part of the floodplain a side channel has already been constructed. During the Room for the River project (2007-2015), another measure has been constructed. As a first rough estimate, an additional side channel in combination with lowering of the flood plain was modelled, see figure 4. 


\subsection{Results: restored balance}

The combination of the side channel along the Pannerdens canal, the combined measure at the Meinerswijk floodplain and the reduced measure Climate Park IJsselgate has a positive effect on the setting of the control structures. Without the compensating measures, the northern control structure would be completely closed in order to prevent that too much discharge is diverted to the IJssel River. With the combination of measures the control range is back on the setting of the reference (roughly the geometrical situation of 2050 including the measures of the Delta Program that do not affect the hydraulic situation around the bifurcation points) and meanwhile, flood levels have dropped considerably. In figure 5, a summary of the results is given.

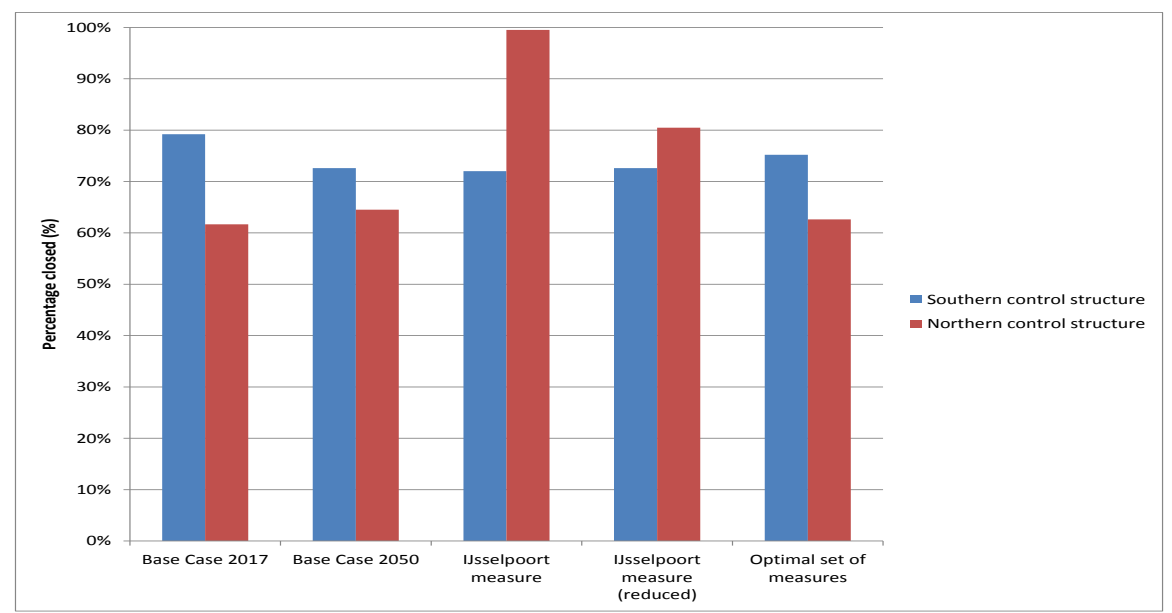

Fig. 5. Overview of required sill elevations in the control structures to maintain the pre-defined discharge partitioning for different situations and a Rhine discharge of $17.000 \mathrm{~m}^{3} / \mathrm{s}$. In blue the position of the southern control structure, in red the position of the northern control structure. The value on the $\mathrm{y}$-axis indicates how far the structure is closed.

The Base Case 2017 describes the position of the sills of both control structures (blue for the southern control structure and red for the northern control structure) with the geometrical situation of 2016 (after completion of Room for the River) and a design discharge at Lobith of $17.000 \mathrm{~m} 3 / \mathrm{s}$. Both structures have some capacity left as they are not fully closed. The Base Case 2050 is the intended situation of the Delta Program, i.e. a series of additional measures along the Rhine branches but without the Climate Park IJsselgate measure. This affects the average setting of the sill level al little bit. Constructing only the Climate Park IJsselgate measure means that the northern control structure is almost completely closed, leaving hardly any possibilities for adjustments. Reducing the effect of the measure by lowering the weirs in Climate Park less improves the situation, but still the northern control structure is $80 \%$ closed (IJsselpoort measure (reduced) in figure 5). The combined set of measures (i.e., a reduced Climate Park IJsselgate, and the additional measures in the Meinerswijk floodplain and the Huissen flood plain) restore the setting of the control structures close to the reference situation of the Base Case 2017 (optimal set of measures in figure 5) and flood levels have dropped considerably. 


\section{Conclusion}

Planning measures around bifurcation points (where a specific discharge partitioning has to be maintained) is a delicate issue. The situation at the Rhine River close to the Dutch-German border is even more complicated because there are two bifurcation points close to each other, there are control structures with a limited capacity and there are restrictions with respect to the discharge partitioning (not only at high discharge conditions but also at low discharge conditions). Due to new safety regulations, the design discharge increases which means that measures have to be taken in order to comply with the new standards in 2050. Measures generally will include a mixture of flood plain measures (which will lower the flood levels) and dike reinforcements (as additional measure).

The first conclusion is that the measure that is planned just downstream of the northern bifurcation point ('Climate park IJsselgate') is actually to massive (when constructed without compensating measures). Flood levels are decreased considerably, but the discharge partitioning is altered in such a way that the agreed discharge partitioning can no longer be maintained. The capacity of the control structures is insufficient for that. Even a reduced measure (which can be achieved by tuning some levees in the area) is not sufficient. These tuning possibilities underline however, the robust character of the measure.

The second conclusion is that there are possibilities to compensate the effect of the reduced measure, with respect to the discharge partitioning. Constructing a side channel at the western flood plains of the Pannerdens Canal (upstream of the northern bifurcation point) diverts discharge to the Nederrijn River. Measures at the Meinerswijk floodplain (downstream of the bifurcation point, but then on another branch) have an additional favorable effect with respect to the average setting of the sills of both control structures. With this combination, enough capacity in the structures is left to use for unexpected developments (uncertainties in the discharge wave or uncertainties in the vegetation configuration).

\section{References}

1. CHR/KHR (1978) Le basin du Rhin. Monograph Hydrologique/Das Rheingebiet, Hydrologische Monographie (The Rhine basin. Hydrological Monograph) (In French and German)

2. Ministry of Infrastructure and Water Management and Ministry of Economic Affairs (2014) Delta Programme 2015, Annual report of the Delta Programme, Working on the delta, The decisions to keep the Netherlands safe and liveable.

3. Schielen, R.M.J., P. Jesse \& L. Bolwidt (2007). On the use of flexible spillways to control the discharge ration of the Rhine in the Netherlands: hydraulic and morphological observations, Netherlands Journal of Geosciences, 86-1.

4. Van Alphen, J. (2016) The Delta Programme and updated flood risk management policies in The Netherlands. Journ. Flood Risk Mngmt. 9, 310-319

5. Van Stokkom, H.T.C., A.J.M. Smits, R.S.E.W. Leuven (2005) Flood Defense in The Netherlands. Water international 30, 76- 87. 